\title{
Separated from Cohabitee
}

National Cancer Institute

\section{Source}

National Cancer Institute. Separated from Cohabitee. NCI Thesaurus. Code C150748.

An indication that an individual is separated from the person with whom they were sharing a home. 